\title{
Immediate and Long-Term Follow-Up of Percutaneous Mitral Commisurotomy in Pregnant Women with Rheumatic Mitral Stenosis: About 246 Cases
}

\author{
Jihad Raoui, $\mathrm{MD}^{1 *}$, Bouthayna Mesmoudi MD², Elizabeth O. Ugoani MD ${ }^{3}$, Soufiane Lamdek ${ }^{4}$, \\ Bendagha Nessma ${ }^{5}$, Pr El Haitam Naima ${ }^{6}$, Fellat Rokiya ${ }^{7}$ \\ ${ }^{I}$ Resident doctor, Department of Cardiology, Ibn Sina University, Morocco \\ ${ }^{2}$ Resident doctor, Cardiology Center in the Mohammed V Military Instruction Hospital, Morocco \\ ${ }^{3}$ Resident doctor, Department of Cardiology B, Ibn Sina University, Morocco \\ ${ }^{4}$ Resident doctor, Department of Cardiology A, Ibn Sina University, Morocco \\ ${ }^{5}$ Cardiologist in department A of cardiology, Ibn Sina university, Morocco \\ ${ }^{6}$ Professor of cardiology in department A, Ibn Sina University, Morocco \\ ${ }^{7}$ Assistant Head of Department Cardiology B, Ibn Sina University, Morocco
}

*Corresponding Author: Jihad Raoui, MD, Resident doctor, Department of Cardiology, Ibn Sina university, E-mail: raoui.jihad@gmail.com

\begin{abstract}
Background \& Objectives: We report 17 years outcome of subsequent pregnancies of women with severe Mitral Stenosis (MS) who underwent Mitral Balloon Valvuloplasty (MBV) during pregnancy and the follow up of the children born of such pregnancies.
\end{abstract}

Methods: A retrospective study of 246 mitral valve dilations performed during pregnancy from 1997 to 2018 in the Cardiology A department, Ibn Sina Teaching hospital Rabat. We analyzed the obstetric outcome and

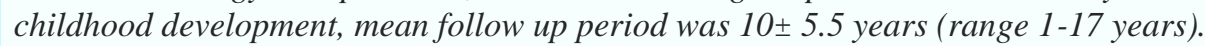

Results: $M B V$ was successful in all patients with improvement in their NYHA class to I/II. All patients underwent obstetrical examination and follow-up, including abdominal and pelvic ultrasound san before and after the intervention. After MBV, patients underwent regular materno-fetal check-up. Labor spontaneously began at $38 \pm 1$ week of amenorrhea; $85 \%$ of our patient had vaginal birth whilst $15 \%$ went through cesarean section for obstetrical reasons. After $M B V$, pregnancy reached full term in $95 \%$ of the cases with a low fetal morbimortality. The long-term follow-up of dilated patients stretched between a period of 5 to 17 years. Within the period of $44 \pm 39$ months, event rate (death, surgery or redilation) was $10 \%$.

In our series the results of BMV during pregnancy were maintained at long term and were superposable to those of non-pregnant dilated patients. Long term follow-up of children born after MBV during pregnancy stretched up to 4 years and showed growth and intellectual development comparable to children of the same age, with a consequent 17-year retrospect showing equivalent results and absence of radiology-induced pathologies thus confirming the innocuousness of $M B V$ during pregnancy.

Conclusion: Mitral Balloon Valvuloplasty is a safe and useful procedure during pregnancy, with no short or long term adverse affects on the mothers and their obstetric future. The children born of subsequent pregnancies exhibited normal physical and mental development.

Keywords: Childhood development, Mitral Balloon Valvuloplasty, Maternal and fetal outcome, Pregnancy.

Abbreviations: New York Heart Association (NYHA); Mitral Balloon Valvuloplasty (MBV); Mitral Stenosis (MS)

\section{INTRODUCTION}

Mitral Balloon Valvuloplasty has been established as an alternative to surgical mitral commissurotomy in the treatment of most patients with symptomatic rheumatic mitral stenosis. [1] Previous reports have demonstrated that MBV can be performed safely during pregnancy in patients with severe mitral stenosis without significant maternal risk or fetal morbidity or mortality. [2] However, at the present time, there are few data on long-term follow-up results after MBV in larger patient populations of pregnant women. [3] The aim of this study was to report immediate and long- 
term outcomes after MBV in a large cohort of pregnant patients with severe mitral stenosis.

\section{METHODS}

This was a retrospective case series of 246 pregnant patients with MS referred to the Cardiology A department, Ibn Sina Teaching hospital Rabat from 1997 to 2018. Our patients' mean age was $28 \pm 5.2$ years and the gestational age $28.1 \pm 4$ weeks of amenorrhea. Mitral stenosis was discovered during pregnancy in $40 \%$ of cases and all 246 patients were primiparous.

94\% of our patients were symptomatic (NHYA stages III to IV), $85 \%$ of patients had sinus rhythm. On cardiac ultrasound imaging, mitral stenosis was severe in all our patients: mean surface area of $0.8 \mathrm{~cm}^{2}$ and $\leq 1 \mathrm{~cm}^{2}$ in $85 \%$ of our cases. They underwent MBV by Inoue balloon catheter technique during the second or third trimester. Abdomen \& pelvic shielding was maintained during the procedure to minimize radiation exposure to the fetuses. Fluoroscopy was used only during trans-sepal puncture and balloon inflation.

Fetal monitoring was carried out during the procedure by cardiotocography. The immediate success of MBV was assessed by increase in mitral valve area and improvement in functional NYHA class. All patients were followed until delivery. The long-term follow-up of dilated patients stretched between a period of 5 to 17 years, of the mothers who underwent MBV during pregnancy and babies born of these pregnancies. This study also includes the subsequent obstetric career of such women and future development of their off springs.

Data were collected by review of the medical records, telephonic and direct communication with the patients. Clinical and echocardiography assessments of the patients were performed initially after 6 months of MBV and annually thereafter. The long term outcome was analyzed for subsequent obstetric course of the mothers and the childhood development of the babies born. Subsequent obstetric future of these women was analyzed for incidence of abortions, still births, pre-term deliveries, and congenital anomalies. Mode of delivery, birth weights and neonatal morbidity or mortality were also recorded. Chi-square test was utilized to determine any significant difference between various modes of delivery, and fetal outcome.
Follow up of children was completed by verbal communication with their mothers and family by obtaining history of milestones, growth, speech, development, recurrent illnesses and any hospital admission. Their learning abilities were assessed by performances at school and compared with their peers and siblings.

\section{Results}

\subsection{Immediate Maternal and Fetal Outcome}

MBV was successful in all patients with significant improvement in their NYHA class to I/II. The pier and post procedural complication rate was $1.8 \%$ : we regret the onset of massive surgical mitral regurgitation in one of our patients who gave birth through cesarean section and had to undergo valve replacement postpartum. A patient presented with tamponade during catheterization and was drained percutaneously after which dilation was successfully carried out. Two patients died of serious stroke. No miscarriage occurred after the procedure.

Labor spontaneously began at $38 \pm 1$ week of amenorrhea; $85 \%$ of our patient had vaginal birth whilst $15 \%$ went through cesarean section for obstetrical reasons. At full term, all patients were hemodynamically stable.

After MBV, pregnancy reached full term in 95\% of the cases with a low fetal morbid-mortality (88\% of the newborns were eutrophic with birth-weight of $2800 \pm 250 \mathrm{~g}$, the average apgar score was $7 \& 2$ at 10 minutes $6 \%$ were hypertrophic and $6 \%$ premature).

\subsection{Long term outcome}

The long-term follow-up of dilated patients stretched between a period of 5 to 17 years. Within the period of $44 \pm 39$ months, event rate (death, surgery or redilation) was $10 \%$. In our series the results of MBV during pregnancy were maintained at long term and were superposable to those of non-pregnant dilated patients. Thus we found the same predictors of rest nose which are: unfavorable valvular anatomy (elevated Wilkins' score, average immediate result, modest surface area post dilation with absence of commissural opening, Mitral regurgitation $>$ grade II).

Long term follow-up of children born after MBV during pregnancy stretched up to 4 years and showed growth and intellectual development comparable to children of the same age, with a consequent 17-year retrospect 
showing equivalent results and absence of radiology-induced pathologies thus confirming the innocuousness of MBV during pregnancy.

\section{DISCUSSION}

The present study demonstrates that MBV is a safe and effective therapeutic procedure for pregnant patients with heart failure secondary to severe rheumatic mitral stenosis.

In agreement with data from previous reports of MBV performed during pregnancy, [4] the present study showed a high clinical success rate of MBV.

Our findings show that, at the present time, MBV should be considered as the first management therapeutic choice for pregnant patients with symptomatic mitral stenosis refractory to optimal medical treatment. The procedure should also be considered for those patients who require prolonged hospitalization, as well as for those who need large amounts of drugs to maintain a compensated clinical state. In this latter group, MBV should be considered to avoid the potential harmful effects of cardiovascular drugs, such as the teratogenic effect, depression of the uterine flow, premature birth, and even interference in the dynamics of labor. [5]

Mitral stenosis is often diagnosed during a pregnancy when a previously asymptomatic woman presents with advanced congestive heart failure. With rest, diuretics, and -blocker use, $73 \%$ of those patients improve in NYHA functional class (from class III or IV to class I or II).

Although surgically closed mitral valve commissurotomy carries a lower risk to the mother, it is associated with a fetal mortality rate of $6 \%$ to $17 \%$. [6] Furthermore, with open surgical commissurotomy performed under general anesthesia and extracorporeal circulation, fetal mortality reaches 33\%. [7-8] MBV can be performed whenever possible, starting from the 12th week of gestation, to avoid the inherent risks of radiation (organogenesis). However, in the presence of unstable clinical conditions, MBV can be performed irrespective of gestational age. Successful MBV during pregnancy should improve the patient's clinical condition, permitting a pregnant woman to return to NYHA functional class I or II as a consequence of improved hemodynamic and mitral valve area [9]. MBV should permit gestation to reach full term, offering the fetus good conditions for adequate intra-uterine development and better clinical conditions to the mother until and during delivery.

In the present study, this principal objective was reached in $99 \%$ of the patients (NYHA functional class I or II) at the moment of delivery. The long-term event-free survival of our pregnant MBV population is superposable to those of non-pregnant dilated patients.

\section{CONCLUSiON}

Rheumatic MS is the commonest cardiac valvular lesion in pregnancy. MS can cause significant maternal as well as fetal mortality and morbidity. Our study further supports the impression that PMV is the procedure of choice to treat pregnant women with rheumatic mitral stenosis in NYHA functional class III or IV and/or unresponsive to adequate medical treatment. In this population, PMV is a safe and effective treatment that results in excellent immediate and long-term outcomes for mothers and their offspring.

\section{REFERENCES}

[1] Inoue K, Owaki T, Nakamura T, Miyamoto N. Clinical application of intravenous mitral commissurotomy by a new balloon catheter. J Thorac Cardiovasc Surg 1984;87:394-402

[2] Palacios IF, Block PC, Wilkins GT, Rediker DE, Dagget WM. Percutaneous mitral balloon valvotomy during pregnancy in a patient with severe mitral stenosis. Cathet Cardiovasc Diagn 1988; 15:109-111.

[3] Mangione JA, Lourenco RM, dos Santos ES, Shigueyuki A, Mauro MF, Cristovao SA, Del Castillo JM, Siqueira EJ, Bayerl DM, Lins Neto OB, Selman AA. Long-term follow-up of pregnant women after percutaneous

[4] Mangione JA, Lourenço RM, dos Santos ES, Shigueyuki A, Mauro MF, Cristovão SA, et al. Long-term follow-up of pregnant women after percutaneous mitral valvuloplasty. Catheter Cardiovasc Interv. 2000;50(4):413-417

[5] Esteves CA, Munoz JS, Braga S, Andrade J, Meneghelo Z, Gomes N, et al. Immediate and long-term follow-up of percutaneous balloon mitral valvuloplasty in pregnant patients with rheumatic mitral stenosis. Am J Cardiol. 2006; 98:812-816.

[6] Mangin M, Ramanah R, Aouar Z, Courtois L, Collin A, Cossa S, et al. Operative delivery data in France for 2007: results of a national survey 
within teaching hospitals. J Gynecol Obstet Biol Reprod (Paris). 2010; 39(2):121-132. doi: 10.1016/j.jgyn.2010.01.002

[7] Mac Dorman MF, Menacker F, Declercq E. Cesarean birth in the United States: epidemiology, trends, and outcomes. Clin Perinatol. 2008; 35(2):293-307. doi:10.1016/j. clp.2008.03.007
[8] Ba'aqeel HS. Cesarean delivery rates in Saudi Arabia: A ten $\neg$ year review. Ann Saudi Med. 2009; 29:179-183.

[9] Martin JA, Hamilton BE, Sutton PD, Ventura SJ, Menacker F, Kirmeyer S, et al. Births: Final data for 2006. Hyattsville, MD: National Center for Health Statistics. (Report No.:57).2009.

Citation: Jihad Raoui, MD, et al,. Immediate and Long-Term Follow-Up of Percutaneous Mitral Commisurotomy in Pregnant Women with Rheumatic Mitral Stenosis: About 246 Cases. ARC Journal of Cardiology. 2020; 6(1): 6-9. doi:dx.doi.org/ 10.20431/2455-5991.0601002.

Copyright: (C) 2020 Authors. This is an open-access article distributed under the terms of the Creative Commons Attribution License, which permits unrestricted use, distribution, and reproduction in any medium, provided the original author and source are credited. 